\title{
T Cells and Gene Regulation: The Switching On and Turning Up of Genes after T Cell Receptor Stimulation in CD8 T Cells
}

\author{
James M. Conley, Michael P. Gallagher and Leslie J. Berg* \\ Department of Pathology, University of Massachusetts Medical School, Worcester, MA, USA
}

Signaling downstream of the T cell receptor (TCR) is directly regulated by the dose and affinity of peptide antigen. The strength of TCR signaling drives a multitude of $T$ cell functions from development to differentiation. CD8 T cells differentiate into a diverse pool of effector and memory cells after activation, a process that is critical for pathogen

OPEN ACCESS

Edited by:

Dietmar Zehn,

Swiss Vaccine Research Institute,

Switzerland

Reviewed by:

Reinhard Obst,

Ludwig-Maximilians-University,

Germany

Daisuke Kamimura, Hokkaido University, Japan Tobias Bopp,

University Medical Center

Mainz, Germany

*Correspondence:

Leslie J. Berg

leslie.berg@umassmed.edu

Specialty section: This article was submitted to

T Cell Biology,

a section of the journal

Frontiers in Immunology

Received: 18 December 2015 Accepted: 15 February 2016

Published: 29 February 2016

Citation:

Conley JM, Gallagher MP and Berg LJ (2016) T Cells and Gene

Regulation: The Switching On and

Turning Up of Genes after T Cell Receptor Stimulation in CD8 T Cells.

Front. Immunol. 7:76.

doi: 10.3389/fimmu.2016.00076 clearance and is highly regulated by TCR signal strength. T cells rapidly alter their gene expression upon activation. Multiple signaling pathways downstream of the TCR activate transcription factors, which are critical for this process. The dynamics between proximal TCR signaling, transcription factor activation and CD8 T cell function are discussed here. We propose that inducible T cell kinase (ITK) acts as a rheostat for gene expression. This unique regulation of TCR signaling by ITK provides a possible signaling mechanism for the promotion of a diverse $T$ cell repertoire in response to pathogen.

Keywords: inducible T cell kinase, TCR signal strength, rheostat, signal transduction, CD8 effector, IRF4

\section{INTRODUCTION}

T cells bind antigen through their T cell receptor (TCR), activating a signaling cascade that leads to proliferation, differentiation, and pathogen clearance. The affinity of a TCR for its cognate antigen has been directly linked to the regulation of thymic selection and the $\mathrm{T}$ cell immune response. Upon receptor activation, tyrosine kinases are phosphorylated, creating signaling complexes at the plasma membrane that activate downstream signal transduction pathways. In response to activation, the $\mathrm{T}$ cell reorganizes its cytoskeleton, changes its metabolism, and alters its gene expression. This review focuses on the signaling pathways that contribute to changes in gene expression. The three main pathways activated through the TCR that control transcription are the MAPK, NF- $\mathrm{KB}$, and calcium pathways. These pathways dramatically alter the expression and nuclear localization of various transcription factors that directly regulate genes involved in $\mathrm{T}$ cell activation $(1,2)$.

$\mathrm{T}$ cells recognize peptide antigens displayed by the major histocompatibility complex (pMHC) on antigen-presenting cells (APCs). The interactions between the TCR and pMHC have been extensively characterized in the context of thymic selection and in the immune response to infection (3). In response to viral infection, CD8 T cells recognize antigen from APCs in the lymphoid organs, undergo clonal expansion, migrate to the site of infection, kill infected cells, and then die by apoptosis. Some of the CD8 T cells will survive this population contraction to form a memory pool (4).

Because $T$ cells are polyclonal and contain variable TCRs, they are able to recognize a wide variety of peptide ligands. These ligands can have variable binding affinities for the TCR, creating a range 
of ligand-binding kinetics (5). This variability contributes to the process of graded TCR signaling, where altered peptide ligands (APLs) can generate different signaling outcomes depending on the binding kinetics of the TCR and PMHC. This review highlights recent advances in the field, which connect proximal TCR signaling and transcription factor activation to changes in CD8 $\mathrm{T}$ cell function.

\section{GRADED TCR STIMULATION AND SIGNAL TRANSDUCTION}

The effect of APLs on the proximal signaling events downstream of the TCR has been extensively examined. In the basal state, the ITAMs of the TCR zeta chains are phosphorylated and bound to inactive Zap70. The dwell time of an agonist-peptide interaction with the TCR is significantly longer than self-peptide interactions, creating a higher probability that a CD8 coreceptor bound to active Lck can be recruited and bind pMHC. This interaction increases complex stability and creates an opportunity for Lck to activate Zap70 by first phosphorylating Y319, relieving the autoinhibited conformation. Further activation of other tyrosine residues increases Lck and Zap70 interactions and further initiates both kinases to create the downstream LAT signaling complex (6). These proximal signaling events are absolutely required for downstream TCR signal transduction $(7,8)$. Using an engineered mutant allele of Zap70, which is sensitive to a small molecule kinase inhibitor, a sharp threshold of signaling was observed downstream of the kinase. Using Nur77-GFP as a readout for TCR signaling, Zap70 was determined to be required for signaling and cell division. This requirement was independent of both the strength of the pMHC-TCR interaction and IL-2 (9).

Not all pathways downstream of the TCR are similarly affected by antigen avidity. The calcium signaling pathway has been shown to be disproportionately affected by weak antigen stimulation $(10-12)$. The MAPK and NF- $\mathrm{BB}$ pathways, while activated by the TCR, have a threshold level of activation that is less affected by weak stimuli. The MAPK pathway starts with Ras activation and subsequently leads to downstream Erk activation and the formation of the transcription factor dimer AP-1. In T cells, Ras is activated downstream of the TCR by RasGRP or SOS. Initially, RasGRP is activated by binding diacylglycerol (DAG), a byproduct of PtdIns $(4,5) \mathrm{P}_{2}\left(\mathrm{PIP}_{2}\right)$ cleavage, followed by phosphorylation by protein kinase $\mathrm{c}(\mathrm{PKC})$ at the plasma membrane. This process is dependent on TCR signal transduction and ultimately on activation of phospholipase C (PLC $\gamma$ ). PLC $\gamma$ activation gradually increases the local concentration of RasGRP at the LAT signaling complex. While this initial signaling event is graded in nature, it rapidly triggers a positive feedback loop. SOS acts as the integration point in this feedback loop; through allosteric binding, SOS substantially increases the GTPase activity of RasGTP (13). This feedback loop ensures that low-affinity TCR ligation can trigger robust Ras activation. Indeed, a digital signal response is observed with p-Erk, with different affinity antigens triggering maximal pathway activation. CD69 was also observed to have this digital response and its expression was highly dependent on the MAPK pathway $(13,14)$.
A similar signaling effect was observed in the NF- $\kappa \mathrm{B}$ pathway. Jurkat cells stimulated with different concentrations of anti-CD3 antibody were able to activate T cells in a graded manner. However, looking at $\mathrm{I} \kappa \mathrm{B} \alpha$ degradation, the pathway was digital in nature with cells forming a bimodal population (15). Using a mutant form of the OT-I TCR (bTMD) having intact antigen-binding capacity but dampened signaling, a defect in PKC recruitment to the immunosynapse was observed shortly after stimulation. This defect leads to impaired CD8 memory formation. However, only a signaling defect in the NF- $\kappa$ B pathway was observed downstream of the TCR suggesting that a small signaling defect in this pathway could impair CD8 differentiation (16). The diverse functions of NF- $\mathrm{\kappa B}$ signaling downstream of the TCR have been extensively reviewed (17).

The quality of the calcium signaling response is highly sensitive to TCR antigen affinity. Specifically, the influx oscillation patterns of this cation are highly mutable $(10,11,18,19)$. Using calcium indicator dyes to measure changes in intracellular ion concentration, changes in both the amplitude and duration of calcium influx have been observed upon stimulation with antigens of different affinities $(10,19)$. Low-affinity pMHC does not trigger robust calcium influx in multiple in vitro $\mathrm{T}$ cell experiments. This has been linked to the regulation of calcium egress from the endoplasmic reticulum, a process that is mediated by the inositol trisphosphate receptor (IP3R) (10). In CD4 T cells, the time of onset for calcium flux was directly proportional to the affinity of the antigen. Weaker pMHC stimulation also reduced the magnitude of the influx peak and the duration of the influx (11). Calcium oscillation patterns have been directly linked to nuclear signaling in $\mathrm{T}$ cells with a non-linear relationship between $\left[\mathrm{Ca}^{2+}\right]$ and transcription factor activation observed (20). Specifically, high frequency oscillation drove both NFAT and NF- $\mathrm{KB}$ activation, whereas low frequency oscillation drove only NF- $\kappa \mathrm{B}$ activation. This, combined with differences in nuclear dwell time $(>15 \mathrm{~m}$ for NF- $\kappa \mathrm{B}$ and $<10 \mathrm{~m}$ for NFAT), accounts for variable pathway activation in response to changes in calcium influx (21).

The calcium-sensitive transcription factor NFAT is well known for its contribution to $\mathrm{T}$ cell activation, specifically through the production of IL-2 and prosurvival factors. NFAT-binding partners are also critical for $\mathrm{T}$ cell activation. Recently, the genetic targets of NFAT were further characterized by comparing constructs that allowed or ablated binding with its most common partner, AP-1. A subset of genes critical for the promotion of CD8 $\mathrm{T}$ cell exhaustion were highly dependent on NFAT, with transcription occurring in the absence of AP-1 (22). The amount of time that NFAT spends inside the nucleus is critical for specific transcriptional targets. Using multiphoton intravital microscopy, the half-lives of NFAT nuclear import and export were calculated to be $\sim 1 \mathrm{~min}$ for import and $\sim 20 \mathrm{~min}$ for export. The tolerance gene Egr2 was sensitive to short low-affinity antigen stimulation, while the effector gene Ifng needed prolonged high-affinity stimulation (23).

The signaling data suggest that certain factors like CD69 and IL-2 are digital in nature, while others like interferon regulatory factor 4 (IRF4) are analog in nature. The strength of TCR stimulus, whether through increased dose or affinity of antigen, is not proportional to the output of the MAPK and NF- $\kappa B$ signaling 
pathways. However, the activation marker IRF4 is proportional to the strength of stimulus (Figure 1).

\section{GRADED TCR SIGNALING AND TRANSCRIPTION FACTORS}

In addition to the canonical transcription factors AP-1, NF- $\mathrm{B}$, and NFAT, which are activated by the TCR, CD8 T cells rely on a diverse set of transcription factors that drive different functions. Recently, the balance of Blimp-1, T-Bet, Bcl-6, and eomesodermin has been linked to changes in CD8 differentiation with high TCR signal strength driving T-Bet and Blimp-1 expression, leading to terminal effector differentiation (24-26). Changes in transcription have also been linked to TCR affinity, specifically the transcription factor IRF4 (27). While it shares homology with other family members like IRF3, Type 1 IFN does not regulate IRF4 (28). Rather, its expression is directly regulated by antigen receptors in both $\mathrm{T}$ cells and $\mathrm{B}$ cells. Undetectable in naive lymphocytes, IRF4 is rapidly upregulated by antigen stimulation and the magnitude of expression is proportional to the strength of stimulus (29). The NF- $\mathrm{BB}$ family transcription factor Rel directly regulates Irf4 at the promoter locus (30). In CD8 T cells, IRF4 expression directly impacts clonal expansion and viral clearance. Specifically, the amount of IRF4 expressed in the CD8 T cell contributed to the expansion of short-lived effector cells (SLECs) (31-33). These terminally differentiated T cells are critical for pathogen control and require robust proliferation before the whole population is eliminated through apoptosis. IRF4 contributes to SLEC functionality by regulating multiple genes associated with glycolysis $(32,34)$. CD8 T cells rapidly shift their metabolism in response to antigen and similar cancer cells, they use glycolytic pathways to increase glucose import providing energy and macromolecules for biomass expansion and division $(35,36)$. IRF4 can also act as a repressor and binds sites in genes

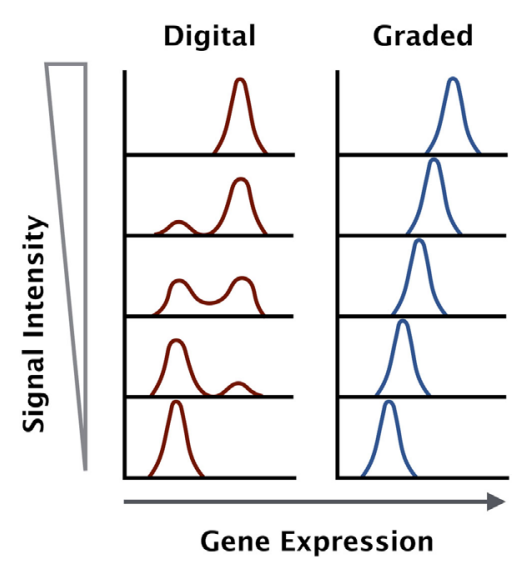

FIGURE 1 | Gene expression outputs downstream of the TCR can be digital or graded in nature. Some genes are upregulated to a maximal level and the increase in antigen dose will increase the percentage of positive cells within a given population (digital), while other genes increase in expression in direct proportion to the antigen dose and affinity across the entire population (graded). associated with apoptosis and cell cycle inhibition, supporting its important role in T cell survival and expansion (33). Directly comparing Irf4 ${ }^{+/-}$with $\operatorname{Irf4^{-/-}}$ and WT mice, viral clearance and SLEC expansion were directly proportional to the maximum level of IRF4 expression. The haplosufficient mice had approximately twofold to fivefold less IRF4 production, a reduction that was mirrored in their ability to clear infection (31).

The frequent binding partner of IRF4, BATF, has also been linked to CD8 T cell expansion. However, unlike IRF4, the levels of expression are not as critical. The two transcription factors are regulators of T-bet and Blimp1 expression, the two transcription factors that drive effector differentiation (37). Interestingly, BATF was determined to act as a "persistence detector" of antigen signaling. Maximum BATF-mediated effector differentiation was only triggered by durable antigen signaling. Late in the $\mathrm{T}$ cell response, BATF could also repress critical genes like perforin and granzyme B, dampening the late effector response (37).

Another factor associated with TCR affinity is Nur77, a transcription factor primarily associated with apoptosis (38). Nur77 is often used as a reporter for TCR activation with its expression proportional to antigen avidity. The amount of Nur77 expression correlates with thymic selection, with negatively selected thymocytes having higher levels than their positively selected counterparts $(39,40)$. Nur77 is rapidly upregulated after antigen stimulation, and its expression is dependent solely on TCR signaling. Using a Nur77-GFP reporter mouse, the levels of GFP were proportional to the affinity of TCR ligand in the OT-I model system, showing a graded expression similar to IRF4 (39).

\section{ITK AND GRADED TCR SIGNAL STRENGTH}

Downstream of Lck, the LAT signaling complex is critical for downstream signaling pathway activation. Inducible $\mathrm{T}$ cell kinase (ITK) is a Tec family tyrosine kinase, which is activated by Lck and phosphorylates PLC $\gamma$. Unlike its sister kinase Bruton's tyrosine kinase (BTK), ITK's expression is largely limited to T cells, and its catalytic activity is in the weak micromolar range. In resting $\mathrm{T}$ cells, ITK resides in the cytosol. Upon activation, the kinase is recruited to the plasma membrane through its pleckstrin homology $(\mathrm{PH})$ domain, which binds $\operatorname{PtdIns}(3,4,5) \mathrm{P}_{3}$ $\left(\mathrm{PIP}_{3}\right)$. ITK also associates with the LAT-SLP76 complex through its $\mathrm{SH} 2$ and $\mathrm{SH} 3$ domains, creating a signaling complex that is directly dependent on upstream Lck and Zap70 signaling. ITK is directly phosphorylated by Lck and subsequently undergoes cis-autophosphorylation. Then, ITK is able to phosphorylate the lipase PLC $\gamma$ that cleaves $\mathrm{PIP}_{2}$ in the plasma membrane, generating the secondary messengers IP3 and DAG. These secondary messengers primarily activate the downstream MAPK, NF- $\kappa$, and calcium signaling pathways (41-43).

Unlike the upstream Src kinases, ITK is not required for T cell activation. Indeed, $I t k$-deficient $\mathrm{T}$ cells are capable of proliferation and cytokine production in response to antigen stimulation (44, 45). Mice lacking ITK are also able to clear pathogens in multiple infection models (46-48). However, Itk-deficient T cells are not normal, and a diminished response is observed rather than an 
ablated response. While the MAPK pathway is only modestly impaired in Itk-deficient $\mathrm{T}$ cells, the magnitude of calcium flux is greatly reduced in response to antigen (12). This reduction in signaling correlates with a reduction in CD8 clonal expansion in response to infection (49). A key set of experiments directly compared kinase dead mutants of Lck and ITK in activated T cells (50). While both mutants inhibited calcium flux in the T cells, the kinases had very different effects on the whole population. The Lck mutants ablated calcium signaling in a proportion of the $\mathrm{T}$ cells, while ITK mutants dampened the calcium response of each cell in the entire population. This suggests a digital regulation of calcium signaling through Lck and an analog regulation through ITK. We propose that ITK and the calcium signaling pathway are critical for maintaining the analog nature of this TCR output (Figure 2).

\section{GRADED TCR SIGNALING AND CD8 T CELL FUNCTION}

CD8 T cell development and function have been studied using the OT-I transgenic mouse model. The OT-I TCR recognizes the SIINFEKL peptide (OVA), an antigen derived from chicken ovalbumin (51). These OT-I T cells are MHC class I restricted, creating a large population of naive CD8 $\mathrm{T}$ cells that recognize the Ova antigen. The OT-I model provides an excellent system to study TCR signal strength because of the exquisitely high-affinity OVA peptide ligand. APLs with single amino acid substitutions greatly reduce TCR-binding affinity while maintaining equivalent MHC-binding capacity. Scientists have also engineered a variety of pathogens to express these APLs, providing excellent infection models to study TCR signal strength in vivo. In the context of CD8 $\mathrm{T}$ cell development in the thymus, graded TCR signal strength drives the balance between positive and negative selection, a process that can directly impact autoimmune disease (52-54).

A series of studies have looked at CD8 $\mathrm{T}$ cell activation in vivo in response to infection and have teased apart contributions between antigen interactions and environmental inflammatory signals. While $\mathrm{T}$ cell expansion was directly proportional to antigen avidity, cytolytic function was more dependent on inflammatory signals $(55,56)$. Using peptide-pulsed dendritic cells with or without Listeria monocytogenes infection, granzyme $\mathrm{B}$ and IFN- $\gamma$ production were only seen in the context of infection. However, IL-2 and the chemokine receptor CCR7 were regulated in the absence of inflammation, and their expression was directly proportional to the avidity of the antigen. The highaffinity IL-2 receptor (CD25) was driven by both signals with its expression proportional to both dose and affinity of the stimulus $(55,57)$. These Listeria experiments show that certain aspects

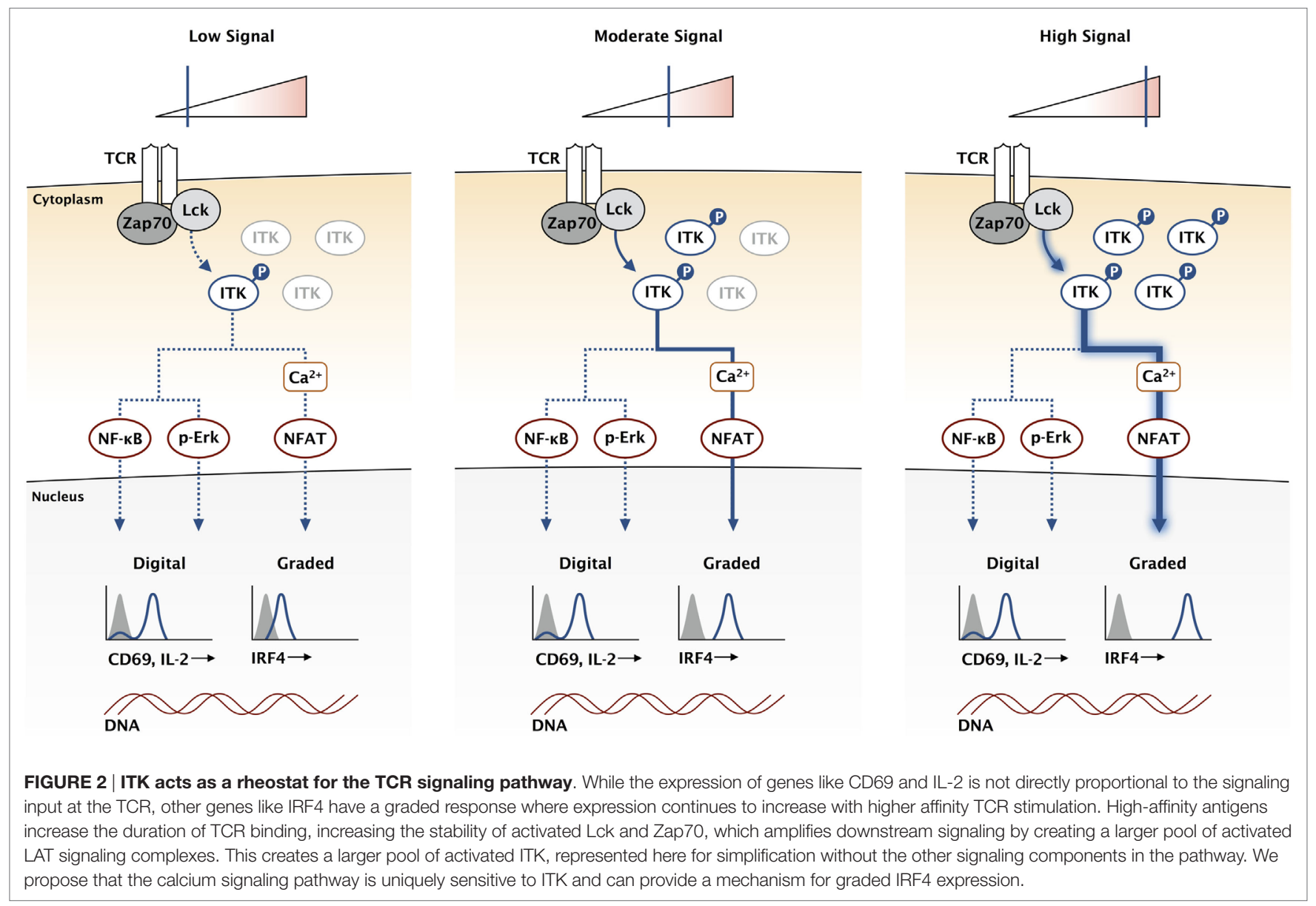


of $\mathrm{T}$ cell function are driven by the affinity of the pMHC-TCR interaction, while others are driven by cytokine activation. Lowaffinity antigen stimulation downregulated CCR7 earlier than high-affinity stimulation and the T cells were able to migrate out of the periarteriolar lymphocyte sheaths (PALS) at an earlier time, creating a larger proportion of $\mathrm{T}$ cells in the blood and the red pulp of the spleen. The high affinity stimulated $\mathrm{T}$ cells retained CCR7 expression out to 4 days and did not migrate out of the PALS. Effects on T cell migration and tissue infiltration were also observed in the context of autoimmunity (57). In a model where membrane-bound ovalbumin (mOVA) is under the control of the rat insulin promoter (RIP), OT-I T cells were transferred into mice after immunization with high- and low-affinity peptide antigen. Only T cells stimulated with high-affinity peptide were able to infiltrate the pancreas and migrate to the site of Ova antigen, a process that was dependent on the integrin VLA-4.

The altered expression in both magnitude and kinetics of CD25, CD69, and CCR7 shows that antigen affinity directly affects IL-2 signaling and lymph node egress. This suggests that $T$ cells stimulated with high-affinity antigen are able to sequester more IL-2 from the environment and remain in the lymph node, thereby allowing them a longer time to receive stimulation. This delay in egress contributes to a more robust clonal expansion, a process that is directly proportional to antigen avidity. Signaling through the IL-2 receptor is required for CD8 memory formation (58). Mice lacking IL-2 receptors in mature CD8 T cells, mixed chimeras that retain a normal population of $\mathrm{T}$ regulatory cells, were able to mount a normal primary response to LCMV infection. However, the secondary response was impaired. Thus, IL-2 signaling is required during the primary response to produce a functional memory pool (59). IL-2 can also promote proliferation of $\mathrm{T}$ cells stimulated by low-affinity antigen. Using an in vitro coculture system of P14 and OT-I CD8 T cells, P14 T cells stimulated with high-affinity GP33 peptide could produce IL-2 and trigger increased proliferation in neighboring OT-I T cells that were stimulated with the low-affinity G4 peptide. The IL-2 is required within $20-30 \mathrm{~h}$ of antigen stimulation and PI3K signaling through the IL-2 receptor cooperates with TCR signaling to promote cell cycle entry (60). IL-2 is not the only secondary signal that cooperates with TCR activation, a wide variety of costimulatory pathways interplay with graded TCR signaling to promote diverse CD8 T cell functions (61). The regulation of T cell memory has been extensively linked to a combination of graded TCR signaling and costimulation using multiple transgenic and pathogen models (24).

Affinity of the antigen has also been linked to regulation of asymmetric cell division with proximal daughter T cells becoming SLECs $(57,62)$. High-affinity interactions led to a distinct

\section{REFERENCES}

1. Chan AC. The role of protein tyrosine kinases and protein tyrosine phosphatases in T cell antigen receptor signal transduction. Annu Rev Immunol (1994) 12:555-92. doi:10.1146/annurev.iy.12.040194.003011

2. Brownlie RJ, Zamoyska R. T cell receptor signalling networks: branched, diversified and bounded. Nat Rev Immunol (2013) 13:257-69. doi:10.1038/ nri3403 progeny after the first division with proximal daughters containing the immunosynapse and increased glycolytic capacity. In contrast, low-affinity TCR interactions did not lead to this phenotype (57). Graded TCR signaling controls many aspects of CD8 T cell differentiation. The signaling mechanisms that connect graded TCR stimulation with these changes in differentiation while not completely understood have been extensively examined in the recent years.

\section{CONCLUSION AND FUTURE DIRECTIONS}

The data generated with the ITK knockout mice suggest that ITK, while not required for pathogen clearance, can act as a rheostat, capable of amplifying or reducing the magnitude of signaling downstream of the TCR. This tuning of signaling can have effects on multiple processes including $\mathrm{T}$ cell development and $\mathrm{T}$ cell differentiation in response to infection. Indeed, Itk-deficient mice have alterations in $\mathrm{T}$ cell development with an increase in innate-like T cells exiting the thymus (63). In response to LCMV infection, Itk-deficient CD8 $\mathrm{T}$ cells had a defect in expansion, very similar to the defect that was seen in Irf4 haplosufficient mice $(31,49)$. Also, expression of IRF4 is highly dependent on ITK activity with a dose proportional reduction observed between IRF4 and ITK inhibition. Our hypothesis is that certain factors like IRF4 depend on TCR signaling for expression, which can be fine-tuned by the rheostat ITK. This can lead to changes in CD8 effector function, providing a link between ITK and CD8 T cell fate. One possible mechanism for this unique level of control is through the calcium pathway. Teasing apart contributions of the different signaling pathways on graded transcription factor expression remains to be done. Directly measuring calcium ion flux in single $\mathrm{T}$ cells in the context of graded TCR signaling in vivo will determine whether calcium signaling alone drives the rheostat activity of ITK. It is also unknown what other genes are regulated in a similar fashion as IRF4. Future experiments will further elucidate the mechanisms connecting graded TCR signaling to changes in transcription and CD8 T cell function.

\section{AUTHOR CONTRIBUTIONS}

JC was the principal writer of this mini review. MG contributed significantly to the design of the figures. All work was done under the direct supervision of LB.

\section{FUNDING}

This work was supported by funding from NIH grants AI101048 and AI106833.

3. Klein L, Kyewski B, Allen PM, Hogquist KA. Positive and negative selection of the T cell repertoire: what thymocytes see (and don't see). Nat Rev Immunol (2014) 14:377-91. doi:10.1038/nri3667

4. Zhang N, Bevan MJ. CD8+ T cells: foot soldiers of the immune system. Immunity (2011) 35:161-8. doi:10.1016/j.immuni.2011.07.010

5. Nikolich-Žugich J, Slifka MK, Messaoudi I. The many important facets of T-cell repertoire diversity. Nat Rev Immunol (2004) 4:123-32. doi:10.1038/ nri1292 
6. Chakraborty AK, Weiss A. Insights into the initiation of TCR signaling. Nat Immunol (2014) 15:798-807. doi:10.1038/ni.2940

7. Au-Yeung BB, Deindl S, Hsu LY, Palacios EH, Levin SE, Kuriyan J, et al. The structure, regulation, and function of ZAP-70. Immunol Rev (2009) 228:41-57. doi:10.1111/j.1600-065X.2008.00753.x

8. Abraham RT, Weiss A. Jurkat T cells and development of the T-cell receptor signalling paradigm. Nat Rev Immunol (2004) 4:301-8. doi:10.1038/ nri1330

9. Au-Yeung BB, Zikherman J, Mueller JL, Ashouri JF, Matloubian M, Cheng DA, et al. A sharp T-cell antigen receptor signaling threshold for T-cell proliferation. Proc Natl Acad Sci U S A (2014) 111:E3679-88. doi:10.1073/ pnas. 1413726111

10. Chen JL, Morgan AJ, Stewart-Jones G, Shepherd D, Bossi G, Wooldridge L, et al. $\mathrm{Ca}^{2+}$ release from the endoplasmic reticulum of NY-ESO-1-specific $\mathrm{T}$ cells is modulated by the affinity of TCR and by the use of the CD8 coreceptor. J Immunol (2010) 184:1829-39. doi:10.4049/jimmunol.0902103

11. Wülfing C, Rabinowitz JD, Beeson C, Sjaastad MD, McConnell HM, Davis MM. Kinetics and extent of T cell activation as measured with the calcium signal. J Exp Med (1997) 185:1815-25. doi:10.1084/jem.185.10.1815

12. Miller AT, Wilcox HM, Lai Z, Berg LJ. Signaling through Itk promotes $\mathrm{T}$ helper 2 differentiation via negative regulation of T-bet. Immunity (2004) 21:67-80. doi:10.1016/j.immuni.2004.06.009

13. Das J, Ho M, Zikherman J, Govern C, Yang M, Weiss A, et al. Digital signaling and hysteresis characterize Ras activation in lymphoid cells. Cell (2009) 136:337-51. doi:10.1016/j.cell.2008.11.051

14. Altan-Bonnet G, Germain RN. Modeling $\mathrm{T}$ cell antigen discrimination based on feedback control of digital ERK responses. PLoS Biol (2005) 3:e356. doi:10.1371/journal.pbio.0030356

15. Kingeter LM, Paul S, Maynard SK, Cartwright NG, Schaefer BC. Cutting edge: TCR ligation triggers digital activation of NF-кB. J Immunol (2010) 185:4520-4. doi:10.4049/jimmunol.1001051

16. Teixeiro E, Daniels MA, Hamilton SE, Schrum AG, Bragado R, Jameson SC, et al. Different $\mathrm{T}$ cell receptor signals determine CD8+ memory versus effector development. Science (2009) 323:502-5. doi:10.1126/science.1163612

17. Paul S, Schaefer BC. A new look at $\mathrm{T}$ cell receptor signaling to nuclear factor. Trends Immunol (2013) 34:269-81. doi:10.1016/j.it.2013.02.002

18. Christo SN, Diener KR, Nordon RE, Brown MP, Griesser HJ, Vasilev K, et al. Scrutinizing calcium flux oscillations in T lymphocytes to deduce the strength of stimulus. Sci Rep (2015) 5:7760. doi:10.1038/srep07760

19. Rosette C, Werlen G, Daniels MA, Holman PO, Alam SM, Travers PJ, et al. The impact of duration versus extent of TCR occupancy on T cell activation: a revision of the kinetic proofreading model. Immunity (2001) 15:59-70. doi:10.1016/S1074-7613(01)00173-X

20. Dolmetsch RE, Xu K, Lewis RS. Calcium oscillations increase the efficiency and specificity of gene expression. Nature (1998) 392:933-6. doi:10.1038/31960

21. Dolmetsch RE, Lewis RS, Goodnow CC, Healy JI. Differential activation of transcription factors induced by $\mathrm{Ca} 2+$ response amplitude and duration. Nature (1997) 386:855-8. doi:10.1038/386855a0

22. Martinez GJ, Pereira RM, Äijö T, Kim EY, Marangoni F, Pipkin ME, et al. The transcription factor NFAT promotes exhaustion of activated CD8+ T cells. Immunity (2015) 42:265-78. doi:10.1016/j.immuni.2015.01.006

23. Marangoni F, Murooka TT, Manzo T, Kim EY, Carrizosa E, Elpek NM, et al. The transcription factor NFAT exhibits signal memory during serial $\mathrm{T}$ cell interactions with antigen-presenting cells. Immunity (2013) 38:237-49. doi:10.1016/j.immuni.2012.09.012

24. Daniels MA, Teixeiro E. TCR signaling in T cell memory. Front Immunol (2015) 6:617. doi:10.3389/fimmu.2015.00617

25. Joshi NS, Cui W, Chandele A, Lee HK, Urso DR, Hagman J, et al. Inflammation directs memory precursor and short-lived effector CD8+ T cell fates via the graded expression of T-bet transcription factor. Immunity (2007) 27:281-95. doi:10.1016/j.immuni.2007.07.010

26. Kaech SM, Cui W. Transcriptional control of effector and memory CD8. Nat Rev Immunol (2012) 12:749-61. doi:10.1038/nri3307

27. Huber M, Lohoff M. IRF4 at the crossroads of effector T-cell fate decision. Eur J Immunol (2014) 44:1886-95. doi:10.1002/eji.201344279

28. Honda K, Taniguchi T. IRFs: master regulators of signalling by toll-like receptors and cytosolic pattern-recognition receptors. Nat Rev Immunol (2006) 6:644-58. doi:10.1038/nri1900
29. Nayar R, Enos M, Prince A, Shin H, Hemmers S, Jiang JK, et al. TCR signaling via Tec kinase ITK and interferon regulatory factor 4 (IRF4) regulates CD8+ T-cell differentiation. Proc Natl Acad Sci U S A (2012) 109:E2794-802. doi:10.1073/pnas.1205742109

30. Grumont RJ, Gerondakis S. Rel induces interferon regulatory factor 4 (IRF-4) expression in lymphocytes: modulation of interferon-regulated gene expression by Rel/nuclear factor kappaB. J Exp Med (2000) 191:1281-92. doi:10.1084/jem.191.8.1281

31. Nayar R, Schutten E, Bautista B, Daniels K, Prince AL, Enos M, et al. Graded levels of IRF4 regulate CD8+ T cell differentiation and expansion, but not attrition, in response to acute virus infection. J Immunol (2014) 192:5881-93. doi:10.4049/jimmunol.1303187

32. Man K, Miasari M, Shi W, Xin A, Henstridge DC, Preston S, et al. The transcription factor IRF4 is essential for TCR affinity-mediated metabolic programming and clonal expansion of T cells. Nat Immunol (2013) 14:1155-65. doi:10.1038/ni.2710

33. Yao S, Buzo BF, Pham D, Jiang L, Taparowsky EJ, Kaplan MH, et al. Interferon regulatory factor 4 sustains CD8+ T cell expansion and effector differentiation. Immunity (2013) 39:833-45. doi:10.1016/j.immuni.2013.10.007

34. Man K, Kallies A. Synchronizing transcriptional control of T cell metabolism and function. Nat Rev Immunol (2015) 15:574-84. doi:10.1038/nri3874

35. Pearce EL, Walsh MC, Cejas PJ, Harms GM, Shen H, Wang LS, et al. Enhancing CD8 T-cell memory by modulating fatty acid metabolism. Nature (2009) 460:103-7. doi:10.1038/nature08097

36. Pearce EL, Poffenberger MC, Chang CH, Jones RG. Fueling immunity: insights into metabolism and lymphocyte function. Science (2013) 342:1242454. doi:10.1126/science.1242454

37. Kurachi M, Barnitz RA, Yosef N, Odorizzi PM, DiIorio MA, Lemieux ME, et al. The transcription factor BATF operates as an essential differentiation checkpoint in early effector CD8+ T cells. Nat Immunol (2014) 15:373-83. doi:10.1038/ni.2834

38. Woronicz JD, Calnan B, Ngo V, Winoto A. Requirement for the orphan steroid receptor Nur77 in apoptosis of T-cell hybridomas. Nature (1994) 367:277-81. doi:10.1038/367277a0

39. Moran AE, Holzapfel KL, Xing Y, Cunningham NR, Maltzman JS, Punt J, et al. $\mathrm{T}$ cell receptor signal strength in Treg and iNKT cell development demonstrated by a novel fluorescent reporter mouse. J Exp Med (2011) 208:1279-89. doi:10.1084/jem.20110308

40. Baldwin TA, Hogquist KA. Transcriptional analysis of clonal deletion in vivo. J Immunol (2007) 179:837-44. doi:10.4049/jimmunol.179.2.837

41. Berg LJ, Finkelstein LD, Lucas JA, Schwartzberg PL. Tec family kinases in T lymphocyte development and function. Annu Rev Immunol (2005) 23:549-600. doi:10.1146/annurev.immunol.22.012703.104743

42. Schwartzberg PL, Finkelstein LD, Readinger JA. Tec-family kinases: regulators of T-helper-cell differentiation. Nat Rev Immunol (2005) 5:284-95. doi:10.1038/nri1591

43. Berg LJ. Signalling through Tec kinases regulates conventional versus innate CD8(+) T-cell development. Nat Rev Immunol (2007) 7:479-85. doi:10.1038/ nri2091

44. Liao XC, Littman DR. Altered $\mathrm{T}$ cell receptor signaling and disrupted $\mathrm{T}$ cell development in mice lacking Itk. Immunity (1995) 3:757-69. doi:10.1016/1074-7613(95)90065-9

45. Liu KQ, Bunnell SC, Gurniak CB, Berg LJ. T cell receptor-initiated calcium release is uncoupled from capacitative calcium entry in Itk-deficient $\mathrm{T}$ cells. J Exp Med (1998) 187:1721-7. doi:10.1084/jem.187.10.1721

46. Bachmann MF, Littman DR, Liao XC. Antiviral immune responses in Itkdeficient mice. J Virol (1997) 71:7253-7.

47. Schaeffer EM, Debnath J, Yap G, McVicar D, Liao XC, Littman DR, et al. Requirement for Tec kinases Rlk and Itk in T cell receptor signaling and immunity. Science (1999) 284:638-41. doi:10.1126/science.284.5414.638

48. Fowell DJ, Shinkai K, Liao XC, Beebe AM, Coffman RL, Littman DR, et al. Impaired NFATc translocation and failure of Th2 development in Itk-deficient CD4+ T cells. Immunity (1999) 11:399-409. doi:10.1016/ S1074-7613(00)80115-6

49. Atherly LO, Brehm MA, Welsh RM, Berg LJ. Tec kinases Itk and Rlk are required for $\mathrm{CD} 8+\mathrm{T}$ cell responses to virus infection independent of their role in CD4+ T cell help. JImmunol (2006) 176:1571-81. doi:10.4049/ jimmunol.176.6.3842 
50. Donnadieu E, Lang V, Bismuth G, Ellmeier W, Acuto O, Michel F, et al. Differential roles of Lck and Itk in $\mathrm{T}$ cell response to antigen recognition revealed by calcium imaging and electron microscopy. J Immunol (2001) 166:5540-9. doi:10.4049/jimmunol.166.9.5540

51. Hogquist KA, Jameson SC, Heath WR, Howard JL, Bevan MJ, Carbone FR. $\mathrm{T}$ cell receptor antagonist peptides induce positive selection. Cell (1994) 76:17-27. doi:10.1016/0092-8674(94)90169-4

52. Koehli S, Naeher D, Galati-Fournier V, Zehn D, Palmer E. Optimal T-cell receptor affinity for inducing autoimmunity. Proc Natl Acad Sci U S A (2014) 111:17248-53. doi:10.1073/pnas.1402724111

53. Daniels MA, Teixeiro E, Gill J, Hausmann B, Roubaty D, Holmberg K, et al. Thymic selection threshold defined by compartmentalization of Ras/MAPK signalling. Nature (2006) 444:724-9. doi:10.1038/nature05269

54. Enouz S, Carrie L, Merkler D, Bevan MJ, Zehn D. Autoreactive T cells bypass negative selection and respond to self-antigen stimulation during infection. J Exp Med (2012) 209:1769-79. doi:10.1084/jem.20120905

55. Zehn D, Lee SY, Bevan MJ. Complete but curtailed T-cell response to very low-affinity antigen. Nature (2009) 457:211-4. doi:10.1038/nature07657

56. Zehn D, Roepke S, Weakly K, Bevan MJ, Prlic M. Inflammation and TCR signal strength determine the breadth of the T cell response in a Bim-dependent manner. J Immunol (2013) 192:200-5. doi:10.4049/jimmunol.1302289

57. King CG, Koehli S, Hausmann B, Schmaler M, Zehn D, Palmer E. T cell affinity regulates asymmetric division, effector cell differentiation, and tissue pathology. Immunity (2012) 37:709-20. doi:10.1016/j.immuni.2012.06.021

58. Malek TR. The biology of interleukin-2. Annu Rev Immunol (2008) 26:453-79. doi:10.1146/annurev.immunol.26.021607.090357
59. Williams MA, Tyznik AJ, Bevan MJ. Interleukin-2 signals during priming are required for secondary expansion of CD8+ memory T cells. Nature (2006) 441:890-3. doi:10.1038/nature04790

60. Voisinne G, Nixon BG, Melbinger A, Gasteiger G, Vergassola M, AltanBonnet G. T cells integrate local and global cues to discriminate between structurally similar antigens. Cell Rep (2015) 11:1208-19. doi:10.1016/j. celrep.2015.04.051

61. Chen L, Flies DB. Molecular mechanisms of T cell co-stimulation and coinhibition. Nat Rev Immunol (2013) 13:227-42. doi:10.1038/nri3405

62. Chang JT, Palanivel VR, Kinjyo I, Schambach F, Intlekofer AM, Banerjee A, et al. Asymmetric T lymphocyte division in the initiation of adaptive immune responses. Science (2007) 315:1687-91. doi:10.1126/science.1139393

63. Atherly LO, Lucas JA, Felices M, Yin CC, Reiner SL, Berg LJ. The Tec family tyrosine kinases Itk and Rlk regulate the development of conventional CD8+ T cells. Immunity (2006) 25:79-91. doi:10.1016/j.immuni.2006.05.012

Conflict of Interest Statement: The authors declare that the research was conducted in the absence of any commercial or financial relationships that could be construed as a potential conflict of interest.

Copyright (c) 2016 Conley, Gallagher and Berg. This is an open-access article distributed under the terms of the Creative Commons Attribution License (CC BY). The use, distribution or reproduction in other forums is permitted, provided the original author(s) or licensor are credited and that the original publication in this journal is cited, in accordance with accepted academic practice. No use, distribution or reproduction is permitted which does not comply with these terms. 